\section{ОРТОАОНТИЧЕСКАЯ ПОАГОТОВКА}

ПЕРЕА ПРОТЕЗИРОВАНИЕМ

ПРИ ГЕНЕРААИЗОВАННОЙ

ПОВЫШЕННОЙ СТИРАЕМОСТИ ЗУБОВ АЕКОМПЕНСИРОВАННОЙ ФОРМЫ

Наиболее опасным следствием, осложнением повышенной стираемости зубов (ПСЗ) является болевая дисфункция ВНЧС, что характерна для генерализованной декомпенсированной формы со снижением высоты нижнего отдела лица (ВНОЛ) $[2-5,7]$. В результате снижения ВНОЛ при декомпенсированной форме ПСЗ и дорсального смещения суставной головки нижней челюсти в суставе может происходить перерастяжение мышечно-связочного аппарата и спастическое сокращение латеральной крыловидной мышцы. Внутрисуставной диск смещается при этом вперед, а задисковая (биламинарная) зона, богатая нервными окончаниями, сдавливается головкой нижней челюсти, вызывая боль [1]. R. Slavicek (2002), Х.А. Каламкаров (2004) [5, 8] в своих работах подчеркивают, что окклюзионно-артикуляционные нарушения, вызванные ПСЗ, нервномышечные нарушения тесно связаны между собой и взаимо усугубляют друг друга. ПСЗ и снижение ВНОЛ вызывают гипертонус жевательных мышц и их асинхронные сокращения. В то же время дискоординация мышечных сокращений, вызванная другими причинами (парафункции), способствует ПСЗ и смещению нижней челюсти, что может привести к возникновению болевой дисфункции ВНЧС. Для профилактики и раннего лечения такой патологии необходимо провести ортодонтическую подготовку перед восстановлением стертых зубов с целью нормализации положения нижней челюсти в пространстве черепа.

\section{Цель исследования}

Совершенствование ортодонтической подготовки перед протезированием у пациентов с генерализованной повышенной стираемостью декомпенсированной формы.

\author{
Аль-Саггаф Сами \\ Абдулрахман Хусейн \\ аспирант кафедры \\ ортопедической \\ стоматологии ГБОУ ВПО \\ БГМУ, г. Уфа
}

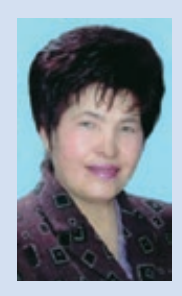

Маннанова Ф.Ф. д.м.н., профессор, зав. кафедрой ортопедической стоматологии ГБОУ ВПО БГМУ, г. Уфа, flora_man@mail.ru

\author{
Алсынбаев Г.Т. \\ аспирант кафедры \\ ортопедической \\ стоматологии ГБОУ ВПО \\ БГМУ, г. Уфа
}

\title{
Резюме
}

Генерализованная повышенная стираемость зубов декомпенсированной формы часто сопровождается выраженными морфофункциональными нарушениями, что требует тщательной диагностики и предварительной подготовки зубочелюстной системы перед окончательным ее восстановлением. Авторами предложены в диагностических целях для уточнения положения нижней челюсти антропометрические приспособления, а также аппараты для нормализации положения нижней челюсти и адаптации жевательных мышц ортодонтическими методами на этапе подготовки к протезированию.

Ключевые слова: повышенная стираемость зубов, диагностика, специальная ортодонтическая подготовка. 


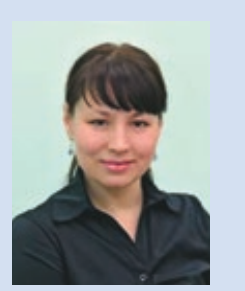

Галиуллина М.В.

к.М.н., доцент кафедры ортопедической стоматологии ГБОУ ВПО БГМУ, г. Уфа

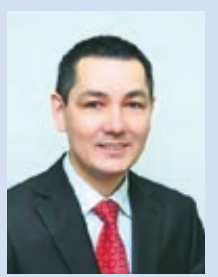

Исхаков И.Р. к.м.н., доцент кафедры ортопедической стоматологии ГБОУ ВПО БГМУ, г. Уфа

Гиззатуллина Ф.В. аспирант кафедры ортопедической стоматологии ГБОУ ВПО БГМУ, г. Уфа

\section{ORTHODONTIC PREPARATION BEFORE PROSTHESIS}

IN GENERALIZED HIGH TEETH ABRASION

\section{DECOMPENSATED FORM}

Al-Caggaf Sami Abdulrahman Hussein, Mannanova F.F., Alsynbaev G.T., Galiullina M.V., Ishakov I.R.,

Gizzatullina F.V.

\section{The summary}

Generalized increased abrasion decompensated forms are often accompanied by severe morphofunctional impairments that require careful diagnosis and preparation of dental system before its final restoration. The authors suggest anthropometric observations for diagnostic aims to clarify the the mandible position, also machines for the normalization of the position of the lower jaw, and adaptation of the masticatory muscles with orthodontic techniques in the stage of preparation for prosthetics.

Keywords: high teeth abrasion, diagnostics, special orthodontic preparation.

\section{Материалы и методы}

В клинике кафедры ортопедической стоматологии было проведено углубленное клиническое обследование 44 пациентов с генерализованной декомпенсированной формой ПСЗ в возрасте от 40 до 60 лет после получения информированного согласия у 40 пациентов женского пола. Из числа мужчин дали на это согласие только 4 человека, поэтому их в анализируемую группу не включили.

При обследовании использовали общепринятые основные и дополнительные методы. Для диагностики декомпенсированных форм (со снижением высоты нижнего отдела лица) измерение проводили, нанося точку в центре у основания перегородки носа до нижнего края подбородка в состоянии привычной окклюзии (высота прикуса). Для определения дистального смещения нижней челюсти при осмотре лица обращали внимание на положение подбородка по сагиттали (профиль лица). При скошенности подбородка и улучшении профиля лица после выдвижения нижней челюсти вперед определяли дистальное ее смещение (симптом Эшлера-Биттнера). Дистальное смещение наблюдали особенно в случаях глубокого прикуса (глубокой резцовой окклюзии) и при двусторонних концевых дефектах зубного ряда в сочетании с ПСЗ и глубоким прикусом.

Для определения боковых (трансверзальных) смещений нами разработан объективный способ измерения с помощью набора устройств для антропометрии. Антропометрическое исследование для определения боковых смещений нижней челюсти по отношению к срединной линии лица (косметическому центру лица) применяли нами разработанный набор, который состоял из приспособления для определения центра подбородка и F-образной линейки (рис. 1).

Предварительно определяли центр подбородка с помощью прозрачного полукруга с концентрическими полукругами и отверстием в центре.
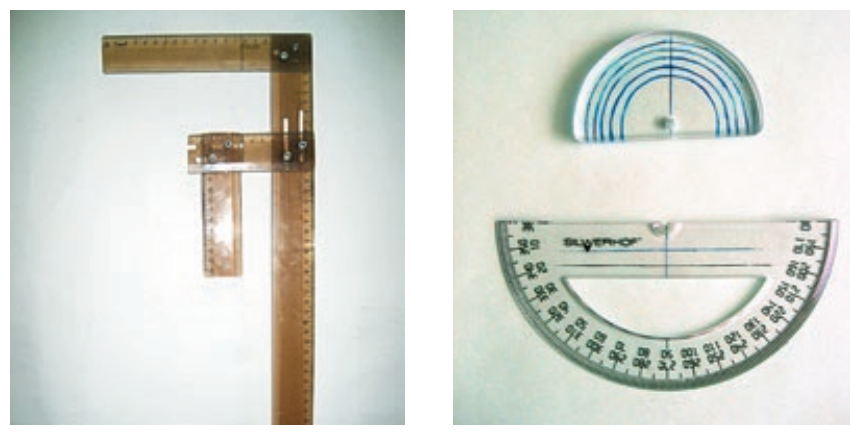

Рис. 1. Антропометр для определения центра подбородка и степени смещения нижней челюсти (Патент РФ №108275 от 20.09.2011 г.) 

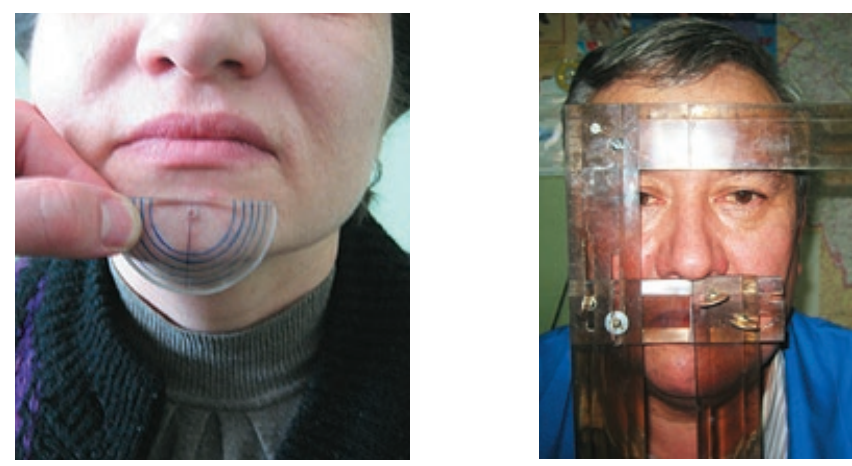

Рис. 2. Определение центра подбородка и смещения нижней челюсти

Подбирая по овалу подбородка соответствующий полукруг приспособления (рис. 2), через отверстие в центре полукруга ставили фломастером точку, соответствующую центру подбородка.

Далее F-образной прозрачной линейкой с перпендикулярной отметкой, которая устанавливается по косметическому центру лица (линия перпендикулярная, проведенная через середину между надбровными дугами и центром основания перегородки носа), измеряли расстояние от этой линии до центра подбородка, определяющее величину смещения подбородка (нижней челюсти) в трансверзальном направлении вправо или влево. В процессе измерения вертикальная линейка подводится к центру подбородка, закрепляется, определяется степень смещения в мм от косметического центра лица (вертикальные отметки на горизонтально расположенной линейке).

Степень смещения нижней челюсти определяли B мм:

I степень - от 1 до 2 мм;

II степень - от 2 до 3 мм;

III степень - более 3 мм.

При совпадении точек в центре на линии, проведенной через середину между надбровными дугами, середину основания перегородки носа, а также через точку в центре подбородка, и при нахождении их на одной линии по центру смещение нижней челюсти отсутствует.

Антропометр позволяет определить расположение межрезцовых центров по отношению к косметическому центру лица при раскрывании губ при сомкнутых зубах в привычной окклюзии или смещение межрезцового центра верхнего зубного ряда и нижнего зубного ряда вправо или влево от этого центра. Имеется возможность измерения отдельных частей лица и их пропорций. Используется для экспресс-диагностики антропометрических нарушений на лице (степень смещения нижней челюсти по трансверзали и снижения нижнего отдела лица). Для измерения высоты нижнего отдела лица пациента просят сомкнуть зубы в привычной окклюзии, в виде касательной подводят отдельную линейку или прозрачный транспортир к нижнему краю подбородка и по вертикальной линейке измеряют расстояние от основания перегородки носа до этой поперечно расположенной под подбородком линейки (транспортира).

Для выявления осложнений со стороны ВНЧС подробно записывали жалобы пациента, собирали анамнез, записывали в карте клинической диагностики функциональных нарушений зубочелюстной системы, по вопроснику (Гамбургское короткое обследование) [6] выясняли ответы на вопросы:

1. Асимметрично ли открывание рта?

2. Открывание рта резко ограниченное или слишком большое?

3. Определяются ли внутрисуставные шумы?

4. Асинхронен ли окклюзионный звук?

5. Болезненна ли пальпация жевательных мышц?

6. Травматична ли эксцентрическая окклюзия зубов?

Пациент расценивается как «функционально здоровый», если только один признак из шести положителен. Два положительных признака показывают на умеренную вероятность дисфункции жевательного аппарата (меньше 40\%). При наличии трех положительных признаков вероятность более высока и приближается к 100\%.

У 29 пациентов с признаками дисфункции ВНЧС и боковыми смещениями нижней челюсти проводили ортодонтическую подготовку с помощью нами разработанного аппарата для нормализации положения нижней челюсти и перестройки миотатического рефлекса перед восстановлением окклюзии ортопедическими методами.

\section{Результаты исследования}

Для изучения и определения функциональных осложнений со стороны мышц и ВНЧС мы провели углубленное исследование среди отобранных 40 человек (женщин) с декомпенсированной формой II, III степени выраженности генерализованной повышенной стираемости зубов (табл. 3). Наши исследования показали, что вторичные боковые смещения нижней челюсти - довольно часто встречающаяся патология (у 29 из 40 обследованных) при декомпенсированной повышенной стираемости зубов и приводит к серьезным осложнениям со стороны жевательных мышц и ВНЧС: появляются суставные шумы (у 21 из 29 обследованных), болезненность при пальпации (курковые зоны) жевательных мышц (у всех 29 
обследованных с боковыми смещениями нижней челюсти) и окклюзионные нарушения (у 18 из 29 обследованных с трансверзальными смещениями нижней челюсти).

Вторичные смещения нижней челюсти и частота

Таблицุа 1 функциональных нарушений у пациенток с декомпенсированной формой генерализованной повышенной стираемости зубов $(n=40)$

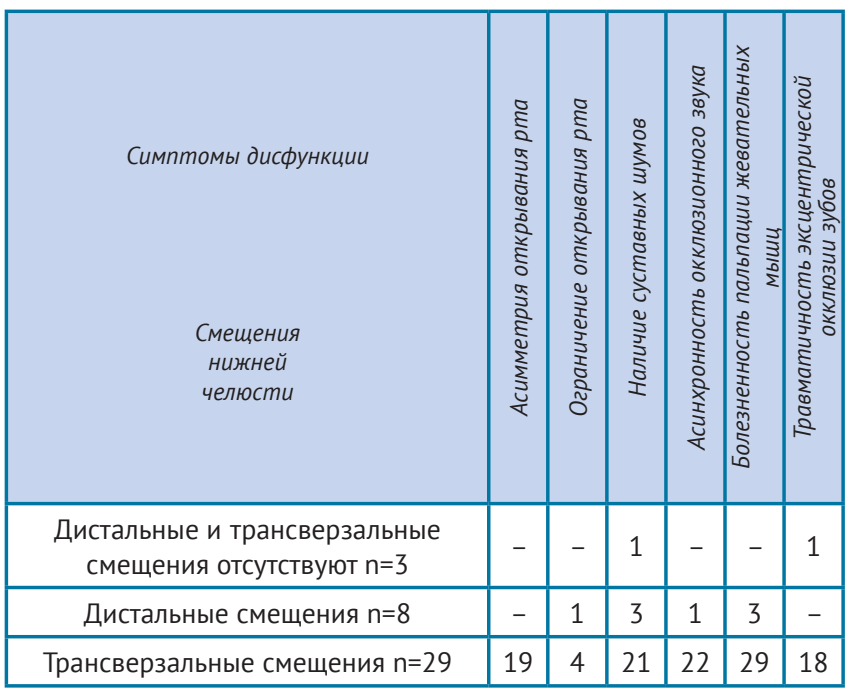

По данным антропометрии уточняли смещения нижней челюсти по сагиттали (дистальное смещение), по трансверзали (боковые смещения вправо и влево от срединной линии лица). При этом провели опрос и Гамбурское короткое обследование (Лебеденко И.Ю. и др., 2006) определяли нарушения со стороны ВНЧС. В то же время без функциональных нарушений среди пациентов с декомпенсированной формой генерализованной повышенной стираемости зубов мы не нашли и утверждаем, что эта группа пациентов требует самого пристального внимания врача-ортопеда при проведении реабилитационных мероприятий на этапах подготовки перед протезированием, а также при окончательном восстановлении зубных рядов и окклюзии ортопедическими конструкциями. Особенно на этапе диагностики рекомендуем применять объективные способы для определения вторичных смещений не только по вертикали и сагиттали, но и по трансверзали, так как вторичные боковые смещения по разным причинам приводят к выраженным осложнениям, особенно со стороны височно-нижнечелюстного сустава. Поэтому этой группе пациентов уделяли особое внимание. Применяли разработанные нами пластинки с боковой наклонной плоскостью (рис. 3) с учетом индивидуальной клинической картины и возраста, эстетиче-

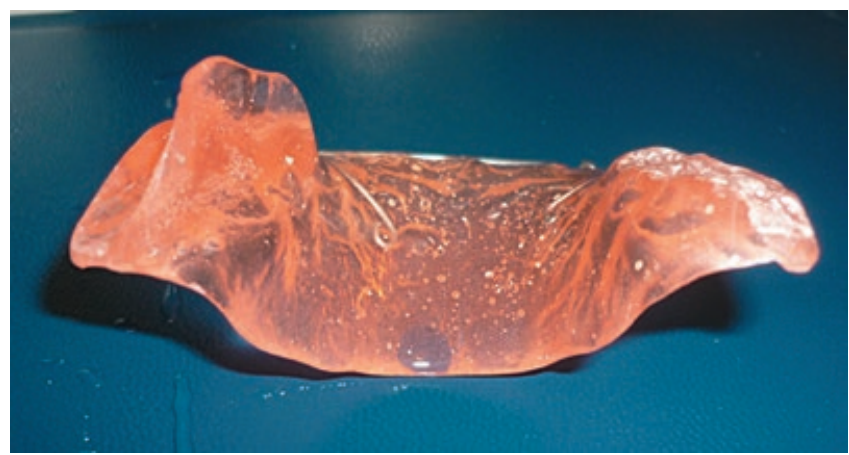

Рис. 3. Каппа с боковой наклонной плоскостью (Патент № 110256 от 20 ноября 2011 г.)

ских требований пациента. Наклонную плоскость корректировали под контролем антропометрии и в зависимости от степени выраженности бокового или сагиттального смещения нижней челюсти, а также от состояния пародонта, степени стертости оставшихся зубов и топографии дефекта зубных рядов.

В качестве клинического примера приводим выписку из истории болезни пациентки С. 48 лет с генерализованной повышенной стираемостью зубов, у которой на этапе ортопедического восстановления зубов и зубных рядов возникло осложнение в виде болевой дисфункции ВНЧС. Были изготовлены восстановительные несъемные металлокерамические протезы, установлены имплантаты для полного замещения дефектов зубного ряда и изготовлен временный съемный пластиночный протез на верхнюю челюсть на период заживления дентальных имплантатов (рис. 4). В полости рта зубная формула:

\section{$\frac{0600321 \text { | } 12305070}{7054321 \mid 12300608}$, ОПтГ - без особых изменений.}

В результате антропометрии в ходе обследования нами определено недостаточное восстановление высоты прикуса, сниженной в результате стирания зубов. Врач также не обратил внимания на смещение нижней челюсти влево в положении привычной окклюзии в результате левостороннего жевания, что, может быть, было и в дальнейшем усилилось после потери зубов и на этапе протезирования вследствие неудобства жевания на правой стороне на съемном протезе. Межрезцовый центр на нижней челюсти смещен влево на 2,5 мм, контакт клыков слева прямой. При сжатии челюстей пациентка испытывает дискомфорт и боль на нижней челюсти слева в области жевательной мышцы и ВНЧС, особенно при пальпации. При возвращении нижней челюсти в нейтральное положение в области суставов пациентка чувствует смыкание челюстей без боли, но 
при этом появляется разобщение протезов слева и челюсть смещается обратно (рис. 4, участок разобщения после нормализации положения нижней челюсти показан стрелкой).

Рекомендован следующий план коррекции изготовленных металлокерамических протезов: учитывая то, что металлокерамические мостовидные протезы были зафиксированы временно, их необходимо снять, изготовить каппу с замещением дефектов и с боковой наклонной плоскостью справа, определив окклюзию в нейтральном положении нижней челюсти (центрация), назначить миогимнастику, массаж, применение мионейростимуляцию жевательных мышц в течение двух месяцев. Контроль состояния жевательных мышц при наличии возможности провести электромиографическим исследованием. После перестройки миотатического рефлекса, при свободном удер- жании нижней челюсти в нейтральном положении и исчезновении болей и дискомфорта скорректировать окклюзионные контакты новых протезов в артикуляторе с лицевой дугой под контролем окклюзографии с помощью аппарата T-Scan и антропометрии лица пациентки в прикусе.

После изготовления каппы с боковой наклонной плоскостью пациентке стало лучше. В дальнейшем будет произведена реконструкция окклюзионной поверхности мостовидных протезов из металлокерамики в конструктивном, определенном и перестроенном в процессе подготовки зубочелюстной системы пациентки в новом положении нижней челюсти по отношению к срединной линии лица.

Подводя итог с учетом всех обстоятельств: жалобы, возникшие у пациентки со стороны ВНЧС вследствие одностороннего жевания, смещения нижней челюсти в левую сторону и образования
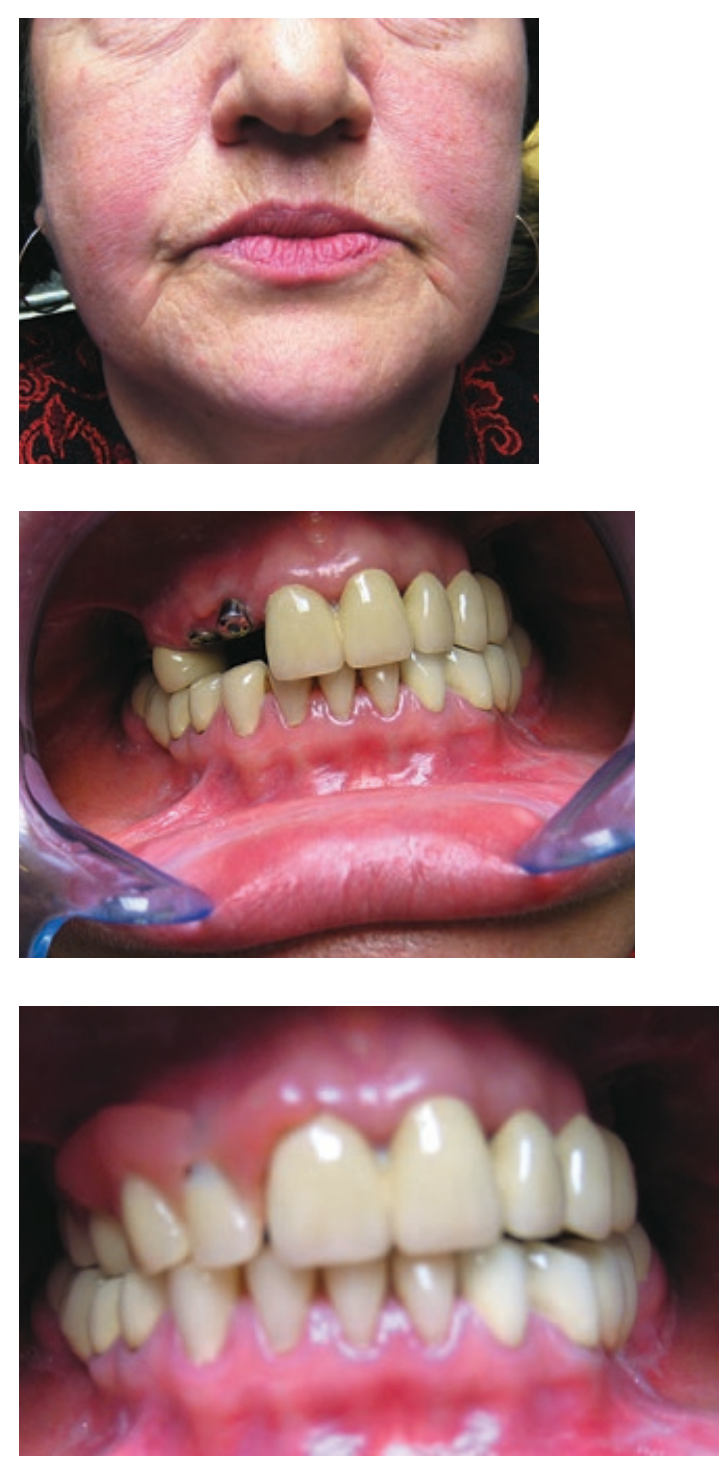
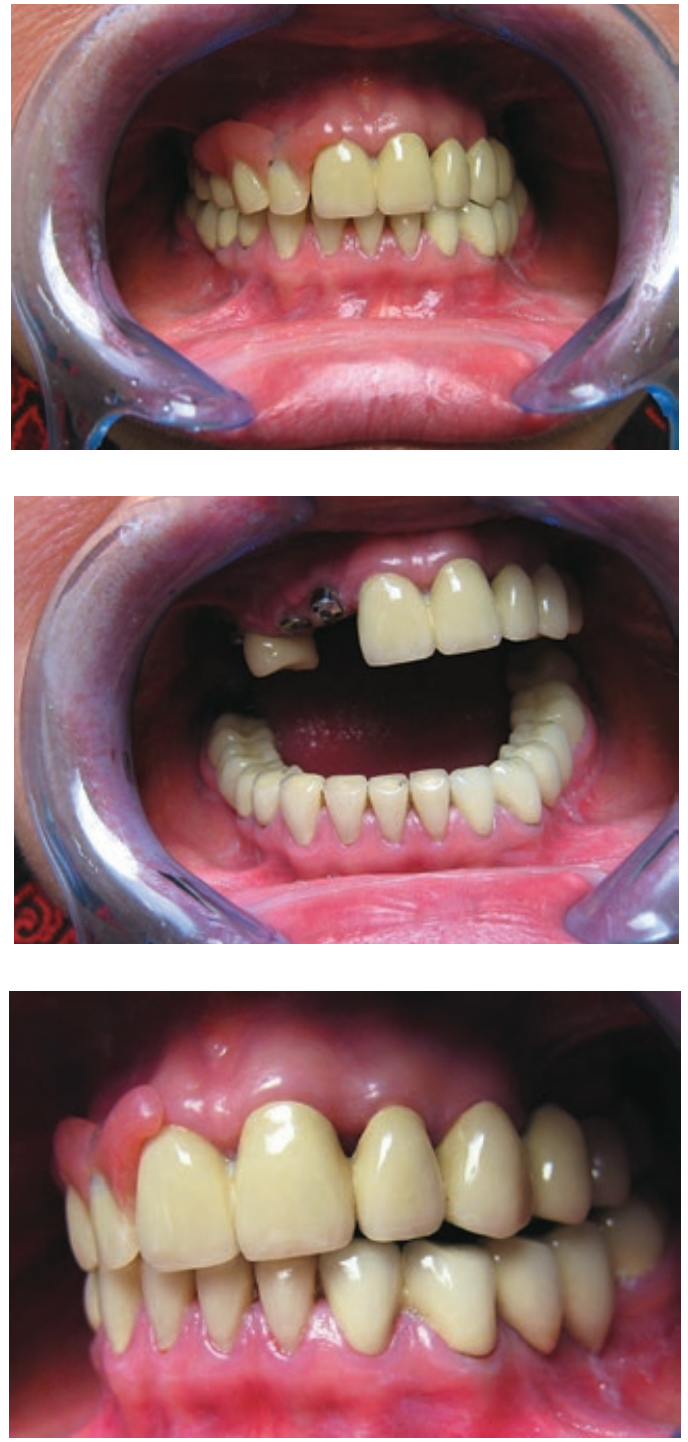

Рис. 4. Фотография лица и полости рта пациентки С. 48 лет 
«привычной окклюзии», привели к болевой ее дисфункции. Без нормализации положения нижней челюсти в данном случае нельзя было начать протезирование. Благодаря только временной фиксации металлокерамического протеза удалось избежать поломки нового протеза во время снятия и изготовления вновь с самого начала, причем полностью пришлось бы это сделать за счет средств лечащего врача, поскольку он не диагностировал левостороннее смещение нижней челюсти, начал протезирование без предварительной подготовки.

Таким образом, наши исследования показали, что при генерализованной повышенной стираемости зубов декомпенсированной формы довольно часто наблюдаются боковые смещения нижней челюсти (29 человек из 40 обследованных), причем чаще наблюдаются функциональные нарушения, особенно со стороны ВНЧС. Своевременно и грамотно проведенные при такой патологии ортодонтические мероприятия несложны для практического врача и приемлемы для пациента, требует достаточного уровня его мотивации и терпения.

\section{ЛИТЕРАТУРА}

1. Зизевский С.А. Ортопедическое лечение дисфункции височнонижнечелюстного сустава.: Дисс. К.М.Н. Казань, 1989. - 142 с.

2. Какосян К.М. Ортопедическое лечение при дисфункции ВНЧС у больных с патологической стираемостью зубов: :автореф. дисс. к.м.н. - М, 1991. - 25 с.

3. Каламкаров Х.А., Бушан М.Т., Жихангиров А. и др. Непосредственные и отдаленные результаты ортопедического лечения патологической стираемости зубов. - Стоматология, 1983, №3. - С. 62-66.

4. Каламкаров Х.А.Ортопедическое лечение патологической стираемости твердых тканей зубов. - М.: Медицина. - 1984. - 176 с.

5. Каламкаров Х.А. Ортопедическое лечение патологической стираемости твердых тканей зубов. - М.: МИА. - 2004. - 176 с.

6. Лебеденко И.Ю., Арутюнов С.Д., Антоник М.М., Ступников А.А. Клинические методы диагностики функциональных нарушений зубочелюстной системы: Учебное пособие. - М.: МЕДпресс-информ. 2006. - 112 с.

7. Bartlett D.V. The role of erosion in tooth wear: actiology, prerention and management./ D.V.Bartlett //International Dentallonrnal. - 2005. - №55. - P. 277-284.

8. Slavicek R. Nhe Masticatori Organ: Functions and Disfunctions Klosterneuburg: Gamma Med.-viss. Fortbilgung-AQ, 2002. - 544 p.

\section{(쇼 CASTELLINI}
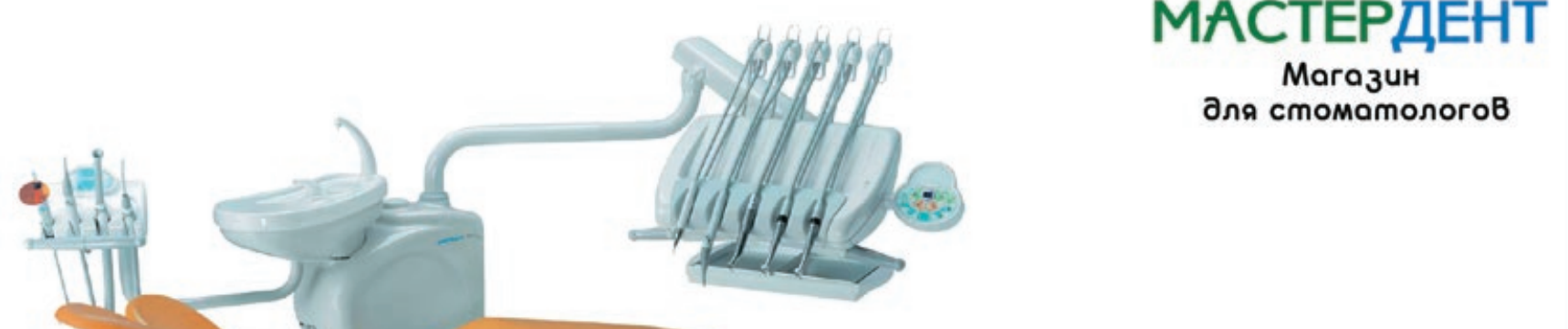

Продукцию Castellini отличают:
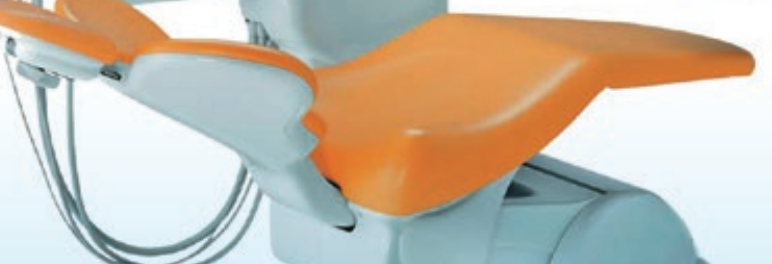

Высокое качество и надежность

Долговечность

Удобство

Стиль и дизайн

Безопасность

Безопасность - фундаментальный стандарт CASTELLINI

UHTEPHET-MARAЗUH

www.masterdent-ural.ru r. Екатеринбург

yก. Чкалова, 124
Офрормить заказ:

(343) $287-50-50$

$200-90-55$ 